IZA DP No. 249

"Should I Pay for You or for Myself"?

The Optimal Level and Composition of Retirement Benefit Systems

Bernard M.S. van Praag

Pedro Cardoso

J anuary 2001 


\title{
"Should I Pay for You or for Myself?" The Optimal Level and Composition of Retirement Benefit Systems
}

\author{
Bernard M.S. van Praag \\ University of Amsterdam and Tinbergen Institute and IZA, Bonn \\ Pedro Cardoso \\ University of Amsterdam and Tinbergen Institute \\ Discussion Paper No. 249 \\ January 2001 \\ IZA \\ P.O. Box 7240 \\ D-53072 Bonn \\ Germany \\ Tel.: +49-228-3894-0 \\ Fax: +49-228-3894-210 \\ Email: iza@iza.org
}

This Discussion Paper is issued within the framework of IZA's research area The Welfare State and Labor Markets. Any opinions expressed here are those of the author(s) and not those of the institute. Research disseminated by IZA may include views on policy, but the institute itself takes no institutional policy positions.

The Institute for the Study of Labor (IZA) in Bonn is a local and virtual international research center and a place of communication between science, politics and business. IZA is an independent, nonprofit limited liability company (Gesellschaft mit beschränkter Haftung) supported by the Deutsche Post AG. The center is associated with the University of Bonn and offers a stimulating research environment through its research networks, research support, and visitors and doctoral programs. IZA engages in (i) original and internationally competitive research in all fields of labor economics, (ii) development of policy concepts, and (iii) dissemination of research results and concepts to the interested public. The current research program deals with (1) mobility and flexibility of labor markets, (2) internationalization of labor markets and European integration, (3) the welfare state and labor markets, (4) labor markets in transition, (5) the future of work, (6) project evaluation and (7) general labor economics.

IZA Discussion Papers often represent preliminary work and are circulated to encourage discussion. Citation of such a paper should account for its provisional character. 
IZA Discussion Paper No. 249

January 2001

\section{ABSTRACT \\ "Should I Pay for You or for Myself?" The Optimal Level and Composition of Retirement Benefit Systems}

Feldstein [1985] posed the questions of what would be the optimal level of retirement benefit, and what would be the optimal mix between the pay-as-you-go system and the funded pension system under the assumption of an exogenous interest rate. We reconsider the problem with the addition of a flexible production function and, consequently, an endogenous interest rate. Moreover, we allow the contributions rate $\theta$ to be negative as well. In the case of a negative $\theta$, the retired subsidize the workers out of their saved capital. This case turns out to be the optimal one in situations of low population growth.

JEL Classification: D91, E21, H55, J14, J26

Keywords: Social security, pay-as-you-go systems, funded pensions, retirement benefits, welfare systems

Bernard M.S. van Praag

University of Amsterdam

Roetersstraat 11

1018 WB Amsterdam

The Netherlands

Tel.: +31 2052560 18/15

Fax: +31205256013

Email: bvpraag@fee.uva.nl. 


\section{Introduction}

In most developed countries there are two types of pension systems. The first is run on a PayAs-You-Go (PAYG) basis, where old-age pensions are financed by a mandatory pay-roll tax paid by the workers. The other system, the Capital Reserve (CR) or funded system, is based on mandatory savings, which are invested in a capital fund; during their retirement the retired live on their savings and interests. The idea of mandatory old-age insurance for workers was first introduced on a large scale by Bismarck in Germany at the end of the $19^{\text {th }}$ century. In the first system workers are supporting the retired. They pay their contributions for others. Under the funded system in contrast the worker invests in a savings fund with the objective to support himself when retired. This essential difference between the two systems lies behind the question in the title of this paper.

As the present workers pay the PAYG-premium for the retired, the ratio between the number of workers and retired, the so-called dependency ratio, is crucial for setting the mandatory contribution rate. Looking back at the period 1950-2000, the dependency ratio has declined from $6: 1$ to about $3: 1$ and it may fall still further during the decades ahead, due to declining birth and mortality rates. For instance, in The Netherlands it will even approach 2:1 in the coming decades (Eurostat [2000]). This puts the political sustainability of the present PAYG system into jeopardy (see also Casamatta, Cremer and Pestieau [2000]). In most western countries a reduction of the relative importance of the PAYG system and a shift to the old-age pension system on a mandatory funded basis is discussed. This implies that workers will save more for their own old age and pay less to their retired colleagues. 
Nowadays the discussion focuses on the so-called 'transition path', where PAYG is gradually and partially replaced by a funded system. This poses some problems, as present workers would have to pay twice, viz., for the currently retired and for their own old age. It appears that the transition path is painful but not impossible (see Conesa and Krueger [1999], Feldstein [1996], and van Praag and van Dalen [1994] for transition issues). For an up-to-date survey of ageing and social security issues we refer to Creedy [1998], Disney [1998] and Mulligan and Sala-i-Martin [1999a].

In practice, in some developed countries a mix of PAYG and funded systems is used to maintain retirement pensions. For the individual contributor and the retired there is no apparent difference between the two systems. The contributor is only interested in the sum of the two contributions, that is, how much he pays in total, while the retired is interested in the sum of the two benefits, that is, how much he gets in total. So, what counts is the level of total contributions and the composition of both benefits. Accordingly we shall speak of the size of the system and its relative composition, by which we mean the mix between PAYG and funding.

The main problem is to determine what is the optimal system size and the optimal mix of both systems. Feldstein [1985] was the first to pose this question. He came to the conclusion that, in some situations, a mix between a funded system and a PAYG system would be optimal, but in a majority of cases a population would be better off with a $100 \%$ funded system and no PAYG system at all.

However, Feldstein's [1985] analysis was a partial one because he started from the assumption that the interest rate is exogenous. Actually, in his analysis the production side was left out. Clearly, as Feldstein himself [1996] argues, the existence of a mandatory PAYG system is likely to reduce savings into funded assets and, consequently, the interest rate might increase 
in the presence of a PAYG system. Evidently, the risk of this will be larger in the case of voluntary savings, which we neglect in this paper, than in the case of mandatory savings for a retirement fund, but it is certainly also present in the latter case.

Since Feldstein's seminal contribution there has been virtually no attention for this basic problem (see also Miles [2000] for a more actuarial approach). The idea that the contributions rate is not an exogenous parameter but an instrument of economic policy with respect to which optimization is possible, is mostly ignored. The gloomy prediction that the PAYG system at its present level will be unsustainable in most countries in the near future, has led some to the conclusion that PAYG systems should be wiped out completely. However, the optimal solution may not be that drastic. It may be that only a change of the system mix is called for: a reduction of the PAYG system to a lower level, and an increase of the mandatory contribution flows through a funded system (for an early example, see van Praag and Poeth [1975]).

In this paper we shall return to Feldstein's original starting point. However, we shall add a flexible production function. We do this in more or less the same simple Feldstein-model with a log-utility function and a Cobb-Douglas production function in a two-period context. We choose this setting without including uncertainty about the future and without assuming a heterogeneous population, in order to be able to study the problem in its most simple and essential setting.

Our findings are, as Feldstein's, that the optimum for the contribution rate $\theta$ and individual savings $S$ depend on the population growth rate $n$, technological growth rate $g$ and time preference rate $\rho$. Besides that, the capital elasticity $\alpha$ in the Cobb-Douglas production function appears to play an important role. 
Without much thought it is frequently assumed that, if there is a PAYG-system, it implies that the workers sustain the old. If, however, the old have acquired a considerable amount of capital and the young have no capital (yet), it is not obvious why the money may not flow inversely, i.e., the old partially support the workers. We will call this the inverse social security case. After all, there is a reciprocal dependency between the generations, as the young provide their labor and the old furnish their capital. Actually, this is still normal in farmers' families in the countryside. If we realize that the difference between paying social security contributions and paying taxes is not that large, the phenomenon of the old paying for the young is not that strange anymore. When we think of the costs of education, the infrastructure, social housing and many other social goods, it is not impossible that the old pay already more than they get back. This would be tantamount to a subsidization of the young generation by the elderly.

If we allow for the possibility that $\theta<0$, where the retired partly sustain the working generation, we see indeed that this arrangement may be the optimal one under several specific parameter configurations. Actually, there is no reason why such a social contract would be unfeasible. However, if we require $\theta \geq 0$, we see that $\theta$ will reach its lower bound zero for a large range of cases. This conforms to Feldstein's results. However, such solutions will be suboptimal compared to the unconstrained solution (i.e., $\theta<0$ ).

The general conclusion of our study is that a mix of both systems should be preferred to a fully funded system. Furthermore, we find that most of the times the optimal situation is a mix of funding and inverse social security $(\theta<0)$. Translated in terms of social policy, this simple model suggests that a downward shift of $\theta$, even to negative values, may become conceivable in the light of the present dramatic changes in demography. 


\section{The Model}

\section{Population}

We assume a population of homogeneous individuals, who live for two periods. In the first period they are employed, and in the second period they are retired.

Each worker embodies $A_{t}$ effective labor units. We assume that productivity grows at the rate $g$ per period, i.e., $A_{t+1}=(1+g) A_{t}$. The labor force grows at the rate $n$ per generation, so $L_{t+1}=(1+n) L_{t}$, where $L_{t}$ represents the number of workers in the economy in period t. This implies that the effective labor force, measured in effective labor units, grows at the rate $(1+g) \times(1+n)$ per period. We will denote the growth rate in effective labor units by $v$, where $(1+g) \times(1+n)=1+v$.

\section{Pay-As-You-Go System}

Workers are assumed to earn a wage rate of $w_{t}$ per effective labor unit per period. There is an old-age pension system run on a Pay-As-You-Go basis. Workers pay a pay-roll tax of $\theta$ over their wages, i.e., they contribute $\theta w_{t}$ to the fund. The sum of contributions to the fund is $\theta w_{t} A_{t} L_{t}$, which is paid out as pensions to the previous cohort numbering $A_{t-1} L_{t-1}$. Hence, the benefit at time $t$ per effective labor unit, is $\theta w_{t}(1+v)$, the benefit per person is $\theta w_{t}(1+v) A_{t-1}$. The remaining labor income is allocated to consumption in the first period and to savings. Workers save an amount $S_{t}$ per effective labor unit. This provides a return that is equal to the 
interest rate $r_{t}$ in period t. In the second period of life individuals consume out of their savings from the first period and the pension from the PAYG social security system.

\section{Capital Stock}

The capital stock is built up from savings of both the working and the retired generation. We assume that, within each period, savings evolve in a linear way. Starting workers do not have savings. When working, individuals gradually put aside some of their labor income, to build a personal pension reserve. Just before retirement these savings peak. During retirement individuals gradually consume their savings and individual savings shrink in a linear way to zero at the time of death. So, the capital stock of the economy is a mix of the savings from the young and working generation and of those from the old and retired generation. The share of each generation in the capital stock of the economy depends on the growth rate of the effective labor units $(v)$.

The aggregate capital stock of the economy evolves according to:

$$
\begin{gathered}
K_{t}=A_{t} L_{t} \frac{1}{2} S_{t}+A_{t-1} L_{t-1} \frac{1}{2} S_{t-1} \\
K_{t}=\frac{1}{2} A_{t} L_{t}\left(S_{t}+\frac{1}{1+v} S_{t-1}\right)
\end{gathered}
$$

where $K_{t}$ is the aggregate capital stock in period t and $S_{t}$ is the amount saved per effective labor unit in period $\mathrm{t}$.

The capital stock per active effective labor unit is: 


$$
\kappa_{t}=\frac{K_{t}}{A_{t} L_{t}}=\frac{1}{2}\left(S_{t}+\frac{1}{1+v} S_{t-1}\right)
$$

\section{Production}

Production $Y_{t}$ is linearly homogeneous in capital $K_{t}$ and effective labor units $A_{t} L_{t}$. Production per effective labor unit is $f\left(\kappa_{t}\right)$, where $\kappa_{t}=\frac{K_{t}}{A_{t} L_{t}}$ stands for capital per active effective labor unit.

When applying Euler's theorem on homogeneous functions, we have:

$$
y_{t}=f\left(\kappa_{t}\right)=f_{\kappa} \kappa_{t}+f_{A_{t} L_{t}}
$$

Assuming profit maximization and perfect competition, the interest and wage rates will equal:

$$
\begin{gathered}
r_{t}=f_{\kappa}\left(\kappa_{t}\right) \\
w_{t}=f\left(\kappa_{t}\right)-r_{t} \kappa_{t}=f\left(\kappa_{t}\right)-f_{\kappa} \kappa_{t}
\end{gathered}
$$




\section{Utility}

We assume a lifetime utility function:

$$
U\left[C_{1}, C_{2}\right]=U_{1}\left[C_{1}\right]+\frac{U_{2}\left[C_{2}\right]}{1+\rho}
$$

where $C_{i},(i=1,2)$, is the consumption level in period $i$ and $\rho$ is the time preference rate.

The profile of consumption for an individual is:

$$
\begin{gathered}
C_{1 t}=(1-\theta) w_{t} A_{t}-S_{t} A_{t} \\
C_{2 t+1}=\theta w_{t+1}(1+v) A_{t}+S_{t} A_{t}\left(1+1 / 2\left(r_{t}+r_{t+1}\right)\right)
\end{gathered}
$$

where $C_{i t}$ is the consumption per individual of age $i$ during period $t$ and where $1 / 2\left(\mathrm{r}_{t}+\mathrm{r}_{t+1}\right)$ stands for the interest on savings, which is consumed during retirement. For simplicity, we exclude compound interest.

Thus, the lifetime utility of an individual can be written as:

$$
U\left[C_{1}, C_{2}\right]=U_{1}\left[(1-\theta) w_{t} A_{t}-S_{t} A_{t}\right]+\frac{U_{2}\left[\theta_{w_{t+1}}(1+v) A_{t}+S_{t} A_{t}\left(\left(1+1 / 2\left(r_{t}+r_{t+1}\right)\right)\right]\right.}{1+\rho}
$$




\section{Stationary optimum}

In this paper we are looking for a stationary optimum. In the steady state all variables per active effective labor unit $(\kappa, y, \theta, w, r, S)$ will be constant. The aggregate variables $\left(Y_{t}, K_{t}\right)$ will increase due to increases in productivity (at the rate $g$ ) and in the labor force (at the rate $n$ ).

In the steady state we have $S_{t}=S_{t-1}=S$ and thus the capital stock per active effective labor unit becomes:

$$
\kappa_{t}=\kappa_{t+1}=\kappa=\frac{1}{2}\left(S_{t}+\frac{1}{1+v} S_{t-1}\right)=\frac{1}{2}\left(\frac{2+v}{1+v}\right) S
$$

We can now write lifetime individual utility in steady-state as:

$$
U=U_{1}[(1-\theta) w A-S A]+\frac{U_{2}[\theta w(1+v) A+S A(1+r)]}{1+\rho}
$$

We want to optimize lifetime utility with respect to savings $(S)$ and with respect to the social security pay-roll contribution rate $(\theta)$. The first-order conditions yield:

$$
\begin{aligned}
& \frac{\partial U}{\partial S}=0 \\
& \quad U_{1}^{\prime}(.) \times\left[(1-\theta) \frac{\partial w}{\partial S} A-A\right]+\frac{U_{2}^{\prime}(.)}{1+\rho} \times\left[\theta \frac{\partial w}{\partial \kappa} \frac{\partial \kappa}{\partial S}(1+v) A+A(1+r)+S A \frac{\partial r}{\partial \kappa} \frac{\partial \kappa}{\partial S}\right]=0
\end{aligned}
$$


$\frac{\partial U}{\partial \theta}=0$

$$
U_{1}^{\prime}(.) \times[-w A]+\frac{U_{2}^{\prime}(.)}{1+\rho} \times[(1+v) w A]=0
$$

After simplifying and rearranging equation (12) we get

$$
\frac{U i(.)}{U_{2}(.)}=\frac{1+v}{1+\rho}
$$

\section{Optimal savings}

When substituting (13) into equation (11) we get:

$$
(1+v) \frac{\partial w}{\partial \kappa} \frac{\partial \kappa}{\partial S}-v+r+S \frac{\partial r}{\partial \kappa} \frac{\partial \kappa}{\partial S}=0
$$

This equation is most intriguing. Optimal capital depends only on the growth rate of the number of effective labor units $(v)$ and on the nature of the production function. Surprisingly, the specification of the utility function (except separability over time) and the time preference $\rho$ are irrelevant for the size of the optimal capital stock. We observe that this does not hold if $\theta$ is fixed beforehand as an exogenous variable. In the latter case equation (12) will not hold and consequently neither will equation (13). But we will turn to this case later.

The real movement of the economy is determined by equation (14), where the only restriction on the utility function is separability. 
It follows that we may distinguish a real side in the economy, i.e., production and distribution in consumption and investment, and a distribution side, which determines the division between the workers and the retired.

Next we assume a Cobb-Douglas production function. The product per effective labor unit is then: $y=f(\kappa)=\kappa^{\alpha}$, where $0 \leq \alpha \leq 1$.

The interest and wage rate in steady-state equal:

$$
\begin{gathered}
r=r(\kappa)=\frac{\partial y}{\partial \kappa}=\alpha \kappa^{\alpha-1} \\
w=w(\kappa)=y-r(\kappa) \times \kappa=\kappa^{\alpha}-\alpha \times \kappa^{\alpha-1} \times \kappa=(1-\alpha) \times \kappa^{\alpha}
\end{gathered}
$$

Using equations (9), (14), (15) and (16) we get the optimal capital stock per effective labor unit:

$$
\kappa=\left[\alpha\left(\frac{1}{v}+\frac{1-\alpha}{2}\right)\right]^{\frac{1}{1-\alpha}}
$$

Equation (17) gives the value of capital stock per effective labor unit in steady-state equilibrium. We see that this yields a real solution if and only if $\frac{1}{v}+\frac{1-\alpha}{2}>0$. If $v>0$, this inequality is always satisfied. This is a relevant remark because there are signs that the population growth rate $(n)$ will become negative in many countries. As $v$ is about $(n+g)$, it may be that the sum remains positive due to a positive $g$. 
From equations (9) and (17) we derive optimal savings per effective labor unit:

$$
S=\frac{2(v+1)}{v+2}\left[\alpha\left(\frac{1}{v}+\frac{1-\alpha}{2}\right)\right]^{\frac{1}{1-\alpha}}
$$

\section{Size of Social Security}

Now we are in a position to look at the optimal social security level $\theta$. From equation (13) we have:

$$
\frac{\left.U_{1}^{\prime}[(1-\theta) w A-S A)\right]}{U_{2}^{\prime}[\theta w(1+v) A+S A(1+r)]}=\frac{1+v}{1+\rho}
$$

Under the assumption of log-utility, the left-hand-side in equation (19) equals just $\mathrm{C}_{2} /$ $\mathrm{C}_{1}$. It follows from equation (19) that the net consumption ratio of the two periods does not depend on $\alpha$ but only on $v$ and $\rho$. That is just on demography, productivity growth and time preference. This result actually holds for any production function.

In order to get a solution, we have to assume a functional specification of the utility function. As usual in the literature, we will assume a logarithmic utility function. Then we are able to solve for the optimal $\theta$.

Departing from equation (19), and using the capital equation (17) and the savings equation (18), we get the optimal pay-roll contributions rate:

$$
\theta=\frac{1}{2+\rho}-\frac{2 \alpha(2+v)}{(1-\alpha)(2+v)(2+\rho)} \times\left[(2+\rho+v)\left(\frac{1}{v}+\frac{1-\alpha}{2}\right)+1+\rho\right]
$$


We see that always $\theta<1 / 2$. It is less clear that $\theta$ is always larger than zero. Indeed it may be that $\theta<0$, which implies that there is a social security transfer from the retired to the workers. In modern industrial states this looks rather unusual. In rural societies income transfers from the retired to their offspring are not unusual.

As we stated earlier, we found that the formula for the optimal contributions rate allows for $\theta$ being negative. We call this the inverse social security case. Although to our knowledge this has nowhere been realized in a formal setting, from our results it will become clear that it is sometimes worthwhile to consider this arrangement.

\section{Sensitivity Analysis}

Next we study the impact of changes in the parameters of our model on the equilibrium values of the capital stock and pay-roll tax.

i) The effect of changes in the capital productivity $\alpha$ on the capital per effective labor unit $\kappa$ is:

$$
\frac{\partial \kappa}{\partial \alpha}=\frac{\left[\left(\frac{1}{v}+\frac{1-\alpha}{2}\right) \times \alpha\right]^{\frac{1}{1-\alpha}}}{1-\alpha} \times\left[\frac{2+v(1-2 \alpha)}{(2+v(1-\alpha)) \alpha}+\frac{\log \left[\left(\frac{1}{v}+\frac{1-\alpha}{2}\right) \times \alpha\right]}{1-\alpha}\right]
$$

Depending on the values of $v$ and $\alpha$, the impact of changes in the capital productivity will be either positive or negative. 
ii) The effect of changes in the productivity and population growth $v$ (i.e., $g+n$ ) on the capital per effective labor unit $\kappa$ is:

$$
\frac{\partial \kappa}{\partial v}=-\frac{\alpha \frac{1}{1-\alpha}}{1-\alpha} \frac{1}{v^{2}}\left(\frac{1}{v}+\frac{1-\alpha}{2}\right)^{\frac{\alpha}{1-\alpha}}
$$

Equation (22) shows that a higher technological progress and/or population growth $(v)$ will lower the value of the capital stock.

iii) The effect of changes in capital productivity $\alpha$ on the pay-roll contributions rate $\theta$ is given by:

$$
\frac{\partial \theta}{\partial \alpha}=-\frac{\left.\left(2(2+\rho)+(3+(\alpha-2) \alpha)(2+\rho) v+(\alpha-1)^{2} v^{2}\right)\right)}{(\alpha-1)^{2}(2+\rho)(2+v) v}
$$

This derivative is negative everywhere. As capital productivity $\alpha$ increases, social security loses its relative advantages. The higher the capital productivity, the less important social security will become. 
iv) The effect of changes in productivity + population growth $v$ on the pay-roll contributions rate $\theta$ is given by:

$$
\frac{\partial \theta}{\partial v}=\frac{\alpha\left(-4\left((v+1)^{2}+1\right)+\rho\left(-4(v+1)+(\alpha-3) v^{2}\right)\right)}{(\alpha-1)(2+\rho) v^{2}(2+v)^{2}}
$$

This derivative will be always positive when the growth in the number of effective labor units is different from zero. So, an increase in the effective population growth leads to an increase in the level of the optimal tax rate.

v) The effect of changes in the time-preference rate $\rho$ on the pay-roll contributions rate $\theta$ is given by:

$$
\frac{\partial \theta}{\partial \rho}=\frac{-2+v(\alpha-1)}{(2+\rho)^{2} \times(2+v)}
$$

This effect is negative; an increase in the time preference rate implies a decrease in the optimal pay-roll contributions rate, when the growth rate of the number of effective labor units is positive. 


\section{Simulations}

In order to get some idea of how the model works, several numerical simulations were performed in different scenarios for different values of the parameters.

As possible values for the capital intensity, we consider the cases where $\alpha$ equals 15,25 , 35 and $45 \%$. The first two values may be considered as realistic. The last two are high but may become realistic as production would become more capital intensive in the future. From the model it follows that the population growth rate $n$ and the technological progress rate $g$ are exchangeable, for it is only their sum $(v)$ which counts. For the annual growth rate of the number of effective labor units we take the values of $1,2,3$ and $4 \%$. Note that this may cover situations of negative population growth $(n)$, countered by strong productivity growth $(g)$. As to the time-preference $(\rho)$ we think that annual rate values of $0,2.5,5$ and $7.5 \%$ are appropriate.

Actually, our model is highly stylized, as we deal with two periods only. In order to get a touch of realism each period is assumed to stand for 35 years. This implies a working period of 35 years and an equally long period of retirement thereafter. Departing from those annual rates, we have computed cumulative values for 35 years. Similar to Feldstein [1985], we may distinguish between annual and corresponding period values for $v$ and $\rho$. All combinations together, we considered 64 different parameter settings. 
Table I: Values of parameters considered

\begin{tabular}{|c|c|c|c|c|c|c|c|c|c|c|c|c|}
\hline \multirow[b]{2}{*}{ per year } & \multicolumn{4}{|l|}{$\alpha$} & \multicolumn{4}{|c|}{$\begin{array}{l}v \\
\text { annual in } \%, \text { period in units }\end{array}$} & \multicolumn{4}{|c|}{$\begin{array}{l}\rho \\
\text { annual in } \% \text {, period in units }\end{array}$} \\
\hline & .15 & .25 & .35 & .45 & 1.0 & 2.0 & 3.0 & 4.0 & 0. & 2.5 & 5. & 7.5 \\
\hline per period & .15 & .25 & .35 & .45 & 0.42 & 1.0 & 1.81 & 2.95 & 0. & 1.37 & 4.52 & 11.6 \\
\hline
\end{tabular}

We now have to distinguish between production variables which depend on $\alpha$ and $v$ only, and distribution variables which depend on the utility function as well, that is, in this case the time preference $\rho$.

This section shows that, in these economies there is a substantial number of cases in which the optimal tax rate $(\theta)$ is negative, i.e., the lifetime utility level of an individual is maximized when there is a transfer from the old to the young generation. This means that young individuals should receive subsidies from the elderly. This is the case of an inverse social security system.

As many politicians and others may find such a situation unrealistic yet, and will rather stick to the constraint $\theta \geq 0$, in those cases where we get a negative $\theta$, we solve the optimization problem under this additional non-negativity constraint as well. The latter cases where we add the non-negativity constraints will be labeled by a letter "I".

Let us now consider one configuration in more detail. Table II shows the results for the configuration. It is configuration number 4 on the Tables III and IV in the appendix. This is the scenario that gives the highest lifetime utility. 
Table II.a: An example of a configuration

\begin{tabular}{ccccccccccccc}
\hline \hline 1 & 2 & 3 & 4 & 5 & 6 & 7 & 8 & 9 & 10 & 11 & 12 & 13 \\
\hline Case. & $\alpha$ & $v \%$ & $\rho \%$ & $\theta$ & Cap & CI & Size & SI & CO/CY & OYI & U & UI \\
4 & 0.15 & 1 & 7.5 & $-48.3 \%$ & 0.361 & 0.094 & 0.858 & 0.702 & 0.113 & 0.482 & -0.625 & -0.837 \\
\hline \hline
\end{tabular}

Table II.b: Outcome of a configuration

\begin{tabular}{ccccccccc}
\hline \hline 14 & 15 & 16 & 17 & 18 & 19 & 20 & 21 & 22 \\
\hline Interest & InterestI & $S Y$ & $S Y I$ & $S G W$ & $S G W I$ & $S N W$ & $S N W I$ & $\theta / S G W$ \\
$0.9 \%$ & $2.2 \%$ & 0.494 & 0.158 & 0.428 & 0.092 & 0.092 & 0.19 & -0.832 \\
\hline \hline
\end{tabular}

The configuration is completely described by columns 2,3 and 4 . This is a case where we find a negative contribution rate to the PAYG system equal to -0.483 . In this case the old subsidize the young, giving them almost half of their wages. The resulting capital stock and production per labor unit are 0.361 (column 6) and 0.858 (8), respectively. The consumption of the old is $11.3 \%$ of that of the young (10) and the (real) interest rate is $36 \%$ per period, which corresponds to about $0.9 \%$ per year. The corresponding utility level (12) over lifetime is -0.625 .

If we exclude the possibility of a transfer from the old to the young, we fix $\theta$ at zero. Then we get the "I" version. Capital per labor unit (column 7) is much lower than before (6). This is so because is harder to save since they do not obtain any subsidies from the elderly. At $2.2 \%$, the (real) annual interest rate (15) is much higher than in the unconstrained case (14), it is more than twice as much. Not surprisingly, here the consumption of the old (11) is relatively higher at $48 \%$ of that of the young. Utility (13) is lower than in the unconstrained case at -0.837 . 
We complete the tables with a few other outcomes. First we look at the savings rate $(S Y)$ (column 16) as a fraction of the production per effective labor unit $y$. We see that it equals 49.4\%. In the constrained case (17) the corresponding figure is only $15.8 \%$. This pattern, which is fairly general, is caused by the fact that, in the case of inverse social security, the elderly subsidize the young, which gives the young more income to save from. Savings as a fraction $(S G W)$ of the gross wages $w$ of the young (18) equals $42.8 \%$, but as a fraction $(S N W)$ of the net wages $(1-\theta) w$ it equals a mere $9.2 \%$. This difference is due to the large contribution from the old to the young. Remain that in this configuration the value of $\theta$ equals minus $48.3 \%$. Finally, we look at the ratio between social security contribution and savings (22), that is the ratio $\theta$ / $S G W$. In the unconstrained case this ratio equals -0.832 . This implies that parents pay more than $80 \%$ of their children's savings. We notice that, in the case $\theta$ is equal to zero, $S N W=S G W$ and hence $\theta$ / SGW is equal to zero.

Next we consider and compare the outcomes for all 64 configurations. The results have been tabulated in Tables III and IV in the Appendix.

\section{Social Security Contributions}

As we observe from the general formula for $\theta$ (equation (20)), the optimal tax rate is always smaller than $50 \%$. In most of the simulations considered the optimal $\theta$ turns out to be negative, when left free. The highest and positive values for the pay-roll tax are found in economies that combine a low capital intensity with a high growth rate of the effective labor population and a small time preference over present consumption. This was certainly the case in most western countries after World War II. When we consider the inverse possibility of social security benefits flowing from the elder to the young, these transfers are more significant when the 
capital intensity is high, the increase in the effective labor population is low and the time preference is high. Indeed, the trend in the world has been towards more capital-intensive production and a slowing-down of population growth. Although institutions are sticky, we observe a trend towards a reduction of social security arrangements which ultimately would tend to $\theta=0$. This model predicts that an extrapolation of this trend to inverse social security is not inconceivable. The optimal contribution rate $\theta$ decreases (in real terms) with an increasing capital share $(\alpha)$, with an increasing time preference factor $(\rho)$, and increases with the growth rate of the number of effective labor units $(v)$. All of these results are intuitively plausible. First, as $\alpha$ becomes larger, this implies that the labor share (1- $\alpha)$ becomes smaller, and so does the basis to collect pay-roll taxes. The interest rate increases with $\alpha$, so private saving becomes more attractive. Put differently, a higher $\alpha$ implies that investment in capital becomes more productive. Second, as people discount the future heavier (higher $\rho$ ), the value of future benefits is smaller in present value, so the optimal benefit will be smaller as well. Third, the rate $v$ can be seen as the return of a PAYG system in an economy in steady state, because it implies an increase in the tax base of the PAYG system. If $v$ falls, positive social security loses its attractions.

In nearly all countries there are only transfers from the young to the elderly $(\theta>0)$. Hence, it would be rather unrealistic if we would not consider that situation as well. What happens if we include the constraint that the social security payroll should be non-negative? When the optimal pay-roll tax $(\theta)$ becomes negative, we set it equal to zero and we solve the optimization problem again. The solution for optimal capital stock is computed, assuming a logutility. All other variables are computed for these new values as well. As expected, we get a lower lifetime utility than in the unconstrained case. 


\section{Savings / Capital Stock}

When regarding optimal savings and capital stock, we observe that, when the contribution to the PAYG system is constrained to be non-negative, the optimal capital stock is smaller than in the unconstrained case. In some scenarios the capital stock in the constrained case is just one third or one quarter of the original value. One possible reason is that young individuals save less because they do not get financial support from the old generation. The interest rate tends to be much higher in the situation where the constraint is active than when we allow for inverse social security. According to our model, the highest values of capital stocks and savings are found in economies where we allow for net transfers from the elderly to the young $(\theta<0)$, where the capital intensity $(\alpha)$ is high and where the growth rate of the effective labor population $(v)$ is small.

An increase in the number of effective labor units leads to a decrease of optimal savings, as the unfunded pension system turns relatively more attractive.

\section{Consumption of the Old versus Consumption of the Young people Ratio}

When there is no social security, this ratio is mostly larger than $100 \%$, and even larger than $200 \%$, when the capital intensity and the growth rate of the effective labor population are large. This situation, where the retired consume more than the workers, is now becoming a reality in many rich welfare states, at least when taking into account that young families are larger than the families of the retired. Obviously, the situation does not hold for all social segments, but it is 
certainly a situation which is looming for the well-integrated social classes. The lowest values are reached when the capital intensity is low and the time preference rate is high. When we introduce social security and allow for transfers from the old to the young this ratio decreases significantly, in most cases to values below $100 \%$. This is an expected outcome as the young receive subsidies from the elderly, so they can consume more than without such subsidies.

\section{Social Security contribution over Savings rate ratio.}

The ratio $(\theta / \mathrm{SGW})$ is almost always smaller than $100 \%$ in absolute terms. The funded pillar of the optimal social security is larger than the pay-as-you-go pillar. We conclude that in most of the types of economies that we considered the CR system or fully-funded pillar of the optimal social security should be larger than the PAYG system or unfunded pillar. It seems that individuals, when transferring income between periods, prefer to use relatively rather a $\mathrm{CR}$ system than a PAYG system. We observe that, as an economy turns relatively more capital intensive, a shift towards a funded system becomes more attractive.

\section{Discussion and conclusions}

In this paper we presented a simple model of social security. This model is a generalization of Feldstein [1985]. The generalization is in two directions. First, we introduce a production function and hence wages and interest become endogenous. Second, we open the possibility that generational transfers go both ways. In other words, we do not only conceive a system where the workers pay for the old, but we also open the possibility that the retired are so rich that they 
can support the young. We call this the case of inverse social security. Our numerical simulations show that there are indeed a number of parameter configurations for which an inverse system would be the optimal system. The case where social security is just zero (the border case) is hardly ever the optimal choice, when the possibility of an inverse system is open. It is observed that the desirability of lowering the social security premium $\theta$ increases when the growth rate $v$ falls. This growth rate is a sum of pure population growth $(n)$ and labor augmenting technological growth $(g)$. It is evident that the population's natural growth rate (immigration excluded) is falling and will become negative, not only in most Western countries but also in other areas like Eastern Europe. As far as this tendency is not sufficiently countered by technological growth, this will ultimately lead to a reduction of traditional retirement benefits and finally to inverse social security. Using a combination of the tax system and the provision of public goods may veil the latter development. In such cases we get doublecounting. Retirement benefit flows are maintained, but the retired pay more taxes than they get back in public provisions, the balance going to the working generation. Apart from the excess burden of rather huge and unnecessary administration costs such an arrangement would involve, it is an elegant way out for avoiding the unpleasant decision of trimming the old-age benefit system.

For countries where we face low or even negative labor population growth rates and where no good social security system exists yet, like in Russia, it may even be argued that the construction of a new social security system on a Pay-As-You-Go basis Western style may be undesirable, because it is out of step with the basic parameters of that society.

In this model we do not pay attention to the possibility of a conflict between the young and the retired. This is not so well conceivable in a stationary situation, because the young 
generation becomes retired in the period ahead and will look at the problem from a lifetime perspective.

Although the present model is still extremely crude and, hence, not an adequate description of the real world, it already suggests that the value of the optimal social security rate $\theta$ critically depends on other system parameters. Here they are admittedly coarsely summarized by one parameter $v$ for labor productivity growth and another parameter $\alpha$ for technology. Moreover, we use one parameter $\rho$ to characterize the preference ordering of society. There is no doubt that such parameters change over time. Therefore, it is impossible to keep the social security system constant over time without incurring welfare losses. The model also suggests that the present situation in many countries may be far from optimal.

In future papers we shall make an attempt to generalize this model to an n-period model with a heterogeneous population. 


\section{References}

Casamatta, G., Cremer, H., Pestieau, P., 2000. Political sustainability and the design of social insurance. Journal of Public Economics, vol. 75 (3), 341-364.

Conesa, J., Krueger, K., 1999. Social Security Reform with Heterogeneous Agents. Review of Economics Dynamics, vol. II, 757-795.

Creedy, J., 1998. Pensions and Population Ageing, Edward Elgar, London.

Disney, R., 1998. Can We Afford to Grow Older?, The MIT Press, Cambridge, MA.

Eurostat, 2000. Eurostat new national baseline population scenarios, Luxembourg.

Feldstein, M., 1985. The Optimal Level of Social Security Benefits. Quarterly Journal of Economics, C, 303-320.

Feldstein, M., 1996. The Missing Piece in Policy Analysis: Social Security Reform. The American Economic Review, Vol. LXXXVI, 1-14.

Miles, D., 2000. Funded and Unfunded Pension Schemes: Risk, Return and Welfare. CESifo Working Paper 239.

Mulligan, C., Sala-i-Martin, X., 1999a. Social Security in Theory and Practice (I): Facts and Political Theories. NBER Working Paper 7118.

1999b. Social Security in Theory and Practice (II): Efficiency Theories, Narrative Theories, and Implications For Reform. NBER Working Paper 7119.

van Praag, B. M. S., Poeth, G., 1975. Introduction of an Old-Age Pensions in a Growing Economy, Journal of Public Economics, Vol. IV, 87-100.

van Praag, B. M. S., van Dalen, H., 1994. Aging Populations and Social Challenges. Paper presented on the International Institute for Applied Systems Analysis's $20^{\text {th }}$ Anniversary, Laxenburg.

Verbon, H, 1988. On The Evolution of Public Pensions Schemes, Offsetdrukkerij Kanters, Amsterdam.

World Bank, 1994. Averting The Old Age Crisis, Oxford University Press, New York. 
Table III.a: Numerical results for various parameters values

\begin{tabular}{|c|c|c|c|c|c|c|c|c|c|c|c|c|c|c|}
\hline 1 & 2 & 3 & $3 a$ & 4 & $4 a$ & 5 & 6 & 7 & 8 & 9 & 10 & 11 & 12 & 13 \\
\hline $\mathrm{CN}$ & $\alpha$ & Annual v & Period v & Annual $\rho$ & Period $\rho$ & $\theta$ & $\kappa$ & $\kappa \mathbf{I}$ & $\mathbf{y}$ & y I & $\begin{array}{c}\text { Con Ratio } \\
\text { Old v } \\
\text { Young }\end{array}$ & $\begin{array}{c}\text { Con Ratio } \\
\text { Old v } \\
\text { Young I }\end{array}$ & LT Utility & $\begin{array}{c}\text { LT Utility } \\
\text { I }\end{array}$ \\
\hline 1 & 0.15 & 0.01 & 0.42 & 0 & 0 & -0.07 & 0.36 & 0.31 & 0.86 & 0.84 & 1.42 & 1.49 & -1.72 & -1.72 \\
\hline 2 & 0.15 & 0.01 & 0.42 & 0.025 & 1.37 & -0.27 & 0.36 & 0.19 & 0.86 & 0.78 & 0.60 & 0.83 & -1.20 & -1.25 \\
\hline 3 & 0.15 & 0.01 & 0.42 & 0.05 & 4.52 & -0.41 & 0.36 & 0.12 & 0.86 & 0.73 & 0.26 & 0.57 & -0.85 & -0.98 \\
\hline 4 & 0.15 & 0.01 & 0.42 & 0.075 & 11.57 & -0.48 & 0.36 & 0.09 & 0.86 & 0.70 & 0.11 & 0.48 & -0.62 & -0.84 \\
\hline 5 & 0.15 & 0.02 & 1 & 0 & 0 & 0.19 & 0.16 & 0.16 & 0.76 & 0.76 & 2.00 & 2.00 & -1.67 & -1.67 \\
\hline 6 & 0.15 & 0.02 & 1 & 0.025 & 1.37 & 0.00 & 0.16 & 0.16 & 0.76 & 0.76 & 0.84 & 0.85 & -1.26 & -1.26 \\
\hline 7 & 0.15 & 0.02 & 1 & 0.05 & 4.52 & -0.14 & 0.16 & 0.10 & 0.76 & 0.71 & 0.36 & 0.60 & -0.95 & -0.99 \\
\hline 8 & 0.15 & 0.02 & 1 & 0.075 & 11.57 & -0.22 & 0.16 & 0.08 & 0.76 & 0.69 & 0.16 & 0.51 & -0.75 & -0.86 \\
\hline 9 & 0.15 & 0.03 & 1.81 & 0 & 0 & 0.28 & 0.10 & 0.10 & 0.71 & 0.71 & 2.81 & 2.81 & -1.50 & -1.50 \\
\hline 10 & 0.15 & 0.03 & 1.81 & 0.025 & 1.37 & 0.09 & 0.10 & 0.10 & 0.71 & 0.71 & 1.19 & 1.19 & -1.25 & -1.25 \\
\hline 11 & 0.15 & 0.03 & 1.81 & 0.05 & 4.52 & -0.04 & 0.10 & 0.09 & 0.71 & 0.70 & 0.51 & 0.63 & -1.00 & -1.00 \\
\hline 12 & 0.15 & 0.03 & 1.81 & 0.075 & 11.57 & -0.11 & 0.10 & 0.07 & 0.71 & 0.67 & 0.22 & 0.54 & -0.82 & -0.87 \\
\hline 13 & 0.15 & 0.04 & 2.95 & 0 & 0 & 0.33 & 0.08 & 0.08 & 0.68 & 0.68 & 3.95 & 3.95 & -1.29 & -1.29 \\
\hline 14 & 0.15 & 0.04 & 2.95 & 0.025 & 1.37 & 0.14 & 0.08 & 0.08 & 0.68 & 0.68 & 1.67 & 1.67 & -1.19 & -1.19 \\
\hline 15 & 0.15 & 0.04 & 2.95 & 0.05 & 4.52 & 0.01 & 0.08 & 0.08 & 0.68 & 0.68 & 0.72 & 0.72 & -1.01 & -1.01 \\
\hline 16 & 0.15 & 0.04 & 2.95 & 0.075 & 11.57 & -0.06 & 0.08 & 0.06 & 0.68 & 0.66 & 0.31 & 0.57 & -0.86 & -0.88 \\
\hline 17 & 0.25 & 0.01 & 0.42 & 0 & 0 & -0.56 & 0.61 & 0.25 & 0.88 & 0.71 & 1.42 & 2.14 & -1.95 & -2.13 \\
\hline 18 & 0.25 & 0.01 & 0.42 & 0.025 & 1.37 & -0.75 & 0.61 & 0.17 & 0.88 & 0.64 & 0.60 & 1.35 & -1.37 & -1.67 \\
\hline 19 & 0.25 & 0.01 & 0.42 & 0.05 & 4.52 & -0.89 & 0.61 & 0.12 & 0.88 & 0.59 & 0.26 & 1.05 & -0.98 & -1.41 \\
\hline 20 & 0.25 & 0.01 & 0.42 & 0.075 & 11.57 & -0.96 & 0.61 & 0.10 & 0.88 & 0.57 & 0.11 & 0.94 & -0.75 & -1.29 \\
\hline 21 & 0.25 & 0.02 & 1 & 0 & 0 & -0.07 & 0.24 & 0.21 & 0.70 & 0.68 & 2.00 & 2.21 & -2.15 & -2.16 \\
\hline 22 & 0.25 & 0.02 & 1 & 0.025 & 1.37 & -0.26 & 0.24 & 0.14 & 0.70 & 0.61 & 0.84 & 1.42 & -1.61 & -1.70 \\
\hline 23 & 0.25 & 0.02 & 1 & 0.05 & 4.52 & -0.39 & 0.24 & 0.10 & 0.70 & 0.56 & 0.36 & 1.12 & -1.24 & -1.45 \\
\hline 24 & 0.25 & 0.02 & 1 & 0.075 & 11.57 & -0.46 & 0.24 & 0.09 & 0.70 & 0.54 & 0.16 & 1.01 & -1.02 & -1.33 \\
\hline 25 & 0.25 & 0.03 & 1.81 & 0 & 0 & 0.10 & 0.14 & 0.14 & 0.61 & 0.61 & 2.81 & 2.81 & -2.16 & -2.16 \\
\hline 26 & 0.25 & 0.03 & 1.81 & 0.025 & 1.37 & -0.08 & 0.14 & 0.12 & 0.61 & 0.59 & 1.19 & 1.48 & -1.71 & -1.72 \\
\hline 27 & 0.25 & 0.03 & 1.81 & 0.05 & 4.52 & -0.20 & 0.14 & 0.09 & 0.61 & 0.54 & 0.51 & 1.18 & -1.38 & -1.48 \\
\hline 28 & 0.25 & 0.03 & 1.81 & 0.075 & 11.57 & -0.27 & 0.14 & 0.07 & 0.61 & 0.52 & 0.22 & 1.07 & -1.17 & -1.36 \\
\hline 29 & 0.25 & 0.04 & 2.95 & 0 & 0 & 0.19 & 0.10 & 0.10 & 0.56 & 0.56 & 3.95 & 3.95 & -2.06 & -2.06 \\
\hline 30 & 0.25 & 0.04 & 2.95 & 0.025 & 1.37 & 0.02 & 0.10 & 0.10 & 0.56 & 0.56 & 1.67 & 1.67 & -1.74 & -1.74 \\
\hline 31 & 0.25 & 0.04 & 2.95 & 0.05 & 4.52 & -0.10 & 0.10 & 0.08 & 0.56 & 0.53 & 0.72 & 1.24 & -1.47 & -1.50 \\
\hline 32 & 0.25 & 0.04 & 2.95 & 0.075 & 11.57 & -0.17 & 0.10 & 0.07 & 0.56 & 0.51 & 0.31 & 1.13 & -1.28 & -1.39 \\
\hline
\end{tabular}


Table III.b: Numerical results for various parameters values

\begin{tabular}{|c|c|c|c|c|c|c|c|c|c|c|c|c|c|c|}
\hline 1 & 2 & 3 & $3 a$ & 4 & $4 a$ & 5 & 6 & 7 & 8 & 9 & 10 & 11 & 12 & 13 \\
\hline $\mathrm{CN}$ & $\alpha$ & Annual v & Period v & Annual $\rho$ & Period $\rho$ & $\theta$ & $\kappa$ & $\kappa \mathbf{I}$ & $\mathbf{y}$ & y I & $\begin{array}{c}\text { Con Ratio } \\
\text { Old v } \\
\text { Young }\end{array}$ & $\begin{array}{c}\text { Con Rt } \\
\text { Old v } \\
\text { Young I }\end{array}$ & LT Utility & $\begin{array}{c}\text { LT Utility } \\
\text { I }\end{array}$ \\
\hline 33 & 0.35 & 0.01 & 0.42 & 0 & 0 & -1.18 & 0.92 & 0.19 & 0.97 & 0.56 & 1.42 & 3.19 & -2.08 & -2.76 \\
\hline 34 & 0.35 & 0.01 & 0.42 & 0.025 & 1.37 & -1.37 & 0.92 & 0.13 & 0.97 & 0.49 & 0.60 & 2.18 & -1.46 & -2.24 \\
\hline 35 & 0.35 & 0.01 & 0.42 & 0.05 & 4.52 & -1.51 & 0.92 & 0.10 & 0.97 & 0.45 & 0.26 & 1.79 & -1.06 & -1.97 \\
\hline 36 & 0.35 & 0.01 & 0.42 & 0.075 & 11.57 & -1.58 & 0.92 & 0.09 & 0.97 & 0.43 & 0.11 & 1.63 & -0.82 & -1.85 \\
\hline 37 & 0.35 & 0.02 & 1 & 0 & 0 & -0.39 & 0.31 & 0.15 & 0.66 & 0.52 & 2.00 & 3.35 & -2.63 & -2.83 \\
\hline 38 & 0.35 & 0.02 & 1 & 0.025 & 1.37 & -0.57 & 0.31 & 0.11 & 0.66 & 0.46 & 0.84 & 2.32 & -1.95 & -2.30 \\
\hline 39 & 0.35 & 0.02 & 1 & 0.05 & 4.52 & -0.70 & 0.31 & 0.08 & 0.66 & 0.42 & 0.36 & 1.92 & -1.52 & -2.04 \\
\hline 40 & 0.35 & 0.02 & 1 & 0.075 & 11.57 & -0.77 & 0.31 & 0.07 & 0.66 & 0.40 & 0.16 & 1.76 & -1.27 & -1.92 \\
\hline 41 & 0.35 & 0.03 & 1.81 & 0 & 0 & -0.11 & 0.16 & 0.13 & 0.53 & 0.49 & 2.81 & 3.50 & -2.85 & -2.88 \\
\hline 42 & 0.35 & 0.03 & 1.81 & 0.025 & 1.37 & -0.28 & 0.16 & 0.09 & 0.53 & 0.43 & 1.19 & 2.45 & -2.20 & -2.35 \\
\hline 43 & 0.35 & 0.03 & 1.81 & 0.05 & 4.52 & -0.40 & 0.16 & 0.07 & 0.53 & 0.40 & 0.51 & 2.05 & -1.79 & -2.09 \\
\hline 44 & 0.35 & 0.03 & 1.81 & 0.075 & 11.57 & -0.47 & 0.16 & 0.06 & 0.53 & 0.38 & 0.22 & 1.88 & -1.55 & -1.97 \\
\hline 45 & 0.35 & 0.04 & 2.95 & 0 & 0 & 0.03 & 0.11 & 0.11 & 0.46 & 0.46 & 3.95 & 3.95 & -2.91 & -2.91 \\
\hline 46 & 0.35 & 0.04 & 2.95 & 0.025 & 1.37 & -0.13 & 0.11 & 0.08 & 0.46 & 0.41 & 1.67 & 2.56 & -2.35 & -2.39 \\
\hline 47 & 0.35 & 0.04 & 2.95 & 0.05 & 4.52 & -0.24 & 0.11 & 0.06 & 0.46 & 0.38 & 0.72 & 2.15 & -1.97 & -2.13 \\
\hline 48 & 0.35 & 0.04 & 2.95 & 0.075 & 11.57 & -0.30 & 0.11 & 0.06 & 0.46 & 0.36 & 0.31 & 1.99 & -1.74 & -2.01 \\
\hline 49 & 0.45 & 0.01 & 0.42 & 0 & 0 & -2.01 & 1.38 & 0.12 & 1.16 & 0.39 & 1.42 & 4.97 & -2.10 & -3.71 \\
\hline 50 & 0.45 & 0.01 & 0.42 & 0.025 & 1.37 & -2.20 & 1.38 & 0.09 & 1.16 & 0.34 & 0.60 & 3.55 & -1.47 & -3.05 \\
\hline 51 & 0.45 & 0.01 & 0.42 & 0.05 & 4.52 & -2.33 & 1.38 & 0.07 & 1.16 & 0.31 & 0.26 & 2.98 & -1.07 & -2.73 \\
\hline 52 & 0.45 & 0.01 & 0.42 & 0.075 & 11.57 & -2.40 & 1.38 & 0.07 & 1.16 & 0.29 & 0.11 & 2.74 & -0.83 & -2.59 \\
\hline 53 & 0.45 & 0.02 & 1 & 0 & 0 & -0.82 & 0.36 & 0.10 & 0.63 & 0.35 & 2.00 & 5.31 & -3.12 & -3.84 \\
\hline 54 & 0.45 & 0.02 & 1 & 0.025 & 1.37 & -0.99 & 0.36 & 0.07 & 0.63 & 0.30 & 0.84 & 3.83 & -2.30 & -3.16 \\
\hline 55 & 0.45 & 0.02 & 1 & 0.05 & 4.52 & -1.11 & 0.36 & 0.06 & 0.63 & 0.28 & 0.36 & 3.23 & -1.82 & -2.84 \\
\hline 56 & 0.45 & 0.02 & 1 & 0.075 & 11.57 & -1.18 & 0.36 & 0.05 & 0.63 & 0.26 & 0.16 & 2.99 & -1.54 & -2.69 \\
\hline 57 & 0.45 & 0.03 & 1.81 & 0 & 0 & -0.39 & 0.17 & 0.08 & 0.45 & 0.32 & 2.81 & 5.60 & -3.65 & -3.94 \\
\hline 58 & 0.45 & 0.03 & 1.81 & 0.025 & 1.37 & -0.55 & 0.17 & 0.06 & 0.45 & 0.28 & 1.19 & 4.07 & -2.77 & -3.25 \\
\hline 59 & 0.45 & 0.03 & 1.81 & 0.05 & 4.52 & -0.66 & 0.17 & 0.05 & 0.45 & 0.26 & 0.51 & 3.46 & -2.26 & -2.93 \\
\hline 60 & 0.45 & 0.03 & 1.81 & 0.075 & 11.57 & -0.73 & 0.17 & 0.04 & 0.45 & 0.24 & 0.22 & 3.21 & -1.98 & -2.78 \\
\hline 61 & 0.45 & 0.04 & 2.95 & 0 & 0 & -0.17 & 0.10 & 0.07 & 0.35 & 0.30 & 3.95 & 5.86 & -3.94 & -4.02 \\
\hline 62 & 0.45 & 0.04 & 2.95 & 0.025 & 1.37 & -0.32 & 0.10 & 0.05 & 0.35 & 0.26 & 1.67 & 4.28 & -3.08 & -3.32 \\
\hline 63 & 0.45 & 0.04 & 2.95 & 0.05 & 4.52 & -0.42 & 0.10 & 0.04 & 0.35 & 0.24 & 0.72 & 3.65 & -2.58 & -2.99 \\
\hline 64 & 0.45 & 0.04 & 2.95 & 0.075 & 11.57 & -0.48 & 0.10 & 0.04 & 0.35 & 0.23 & 0.31 & 3.39 & -2.29 & -2.84 \\
\hline
\end{tabular}


Table IV.a: Further results for various parameters values

\begin{tabular}{|c|c|c|c|c|c|c|c|c|c|c|c|c|c|c|}
\hline 1 & 2 & 3 & $3 a$ & 4 & $4 a$ & 14 & 15 & 16 & 17 & 18 & 19 & 20 & 21 & 22 \\
\hline $\mathrm{CN}$ & $\alpha$ & Annual v & Period v & Annual $\rho$ & Period $\rho$ & $\begin{array}{c}\text { Annual } \\
\text { Interest } \\
\text { Rate }\end{array}$ & $\begin{array}{c}\text { Annual } \\
\text { Interest } \\
\text { Rate I }\end{array}$ & SY & SYI & SGW & SGWI & SNW & SNWI & $\theta$ / SGW \\
\hline 1 & 0.15 & 0.01 & 0.42 & 0 & 0 & $0.9 \%$ & $1.0 \%$ & 0.49 & 0.44 & 0.43 & 0.44 & 0.54 & 0.52 & -0.12 \\
\hline 2 & 0.15 & 0.01 & 0.42 & 0.025 & 1.37 & $0.9 \%$ & $1.4 \%$ & 0.49 & 0.29 & 0.43 & 0.29 & 0.46 & 0.34 & -0.46 \\
\hline 3 & 0.15 & 0.01 & 0.42 & 0.05 & 4.52 & $0.9 \%$ & $1.8 \%$ & 0.49 & 0.20 & 0.43 & 0.20 & 0.41 & 0.23 & -0.70 \\
\hline 4 & 0.15 & 0.01 & 0.42 & 0.075 & 11.57 & $0.9 \%$ & $2.2 \%$ & 0.49 & 0.16 & 0.43 & 0.16 & 0.39 & 0.19 & -0.83 \\
\hline 5 & 0.15 & 0.02 & 1 & 0 & 0 & $1.5 \%$ & $1.5 \%$ & 0.28 & 0.28 & 0.19 & 0.28 & 0.41 & 0.41 & 0.57 \\
\hline 6 & 0.15 & 0.02 & 1 & 0.025 & 1.37 & $1.5 \%$ & $1.5 \%$ & 0.28 & 0.28 & 0.19 & 0.28 & 0.33 & 0.33 & -0.01 \\
\hline 7 & 0.15 & 0.02 & 1 & 0.05 & 4.52 & $1.5 \%$ & $2.0 \%$ & 0.28 & 0.20 & 0.19 & 0.20 & 0.29 & 0.23 & -0.42 \\
\hline 8 & 0.15 & 0.02 & 1 & 0.075 & 11.57 & $1.5 \%$ & $2.4 \%$ & 0.28 & 0.16 & 0.19 & 0.16 & 0.28 & 0.18 & -0.64 \\
\hline 9 & 0.15 & 0.03 & 1.81 & 0 & 0 & $2.0 \%$ & $2.0 \%$ & 0.22 & 0.22 & 0.13 & 0.22 & 0.35 & 0.35 & 1.11 \\
\hline 10 & 0.15 & 0.03 & 1.81 & 0.025 & 1.37 & $2.0 \%$ & $2.0 \%$ & 0.22 & 0.22 & 0.13 & 0.22 & 0.28 & 0.28 & 0.36 \\
\hline 11 & 0.15 & 0.03 & 1.81 & 0.05 & 4.52 & $2.0 \%$ & $2.2 \%$ & 0.22 & 0.19 & 0.13 & 0.19 & 0.24 & 0.23 & -0.16 \\
\hline 12 & 0.15 & 0.03 & 1.81 & 0.075 & 11.57 & $2.0 \%$ & $2.6 \%$ & 0.22 & 0.16 & 0.13 & 0.16 & 0.23 & 0.18 & -0.45 \\
\hline 13 & 0.15 & 0.04 & 2.95 & 0 & 0 & $2.4 \%$ & $2.4 \%$ & 0.18 & 0.18 & 0.10 & 0.18 & 0.32 & 0.32 & 1.53 \\
\hline 14 & 0.15 & 0.04 & 2.95 & 0.025 & 1.37 & $2.4 \%$ & $2.4 \%$ & 0.18 & 0.18 & 0.10 & 0.18 & 0.25 & 0.25 & 0.67 \\
\hline 15 & 0.15 & 0.04 & 2.95 & 0.05 & 4.52 & $2.4 \%$ & $2.4 \%$ & 0.18 & 0.18 & 0.10 & 0.18 & 0.22 & 0.22 & 0.06 \\
\hline 16 & 0.15 & 0.04 & 2.95 & 0.075 & 11.57 & $2.4 \%$ & $2.7 \%$ & 0.18 & 0.15 & 0.10 & 0.15 & 0.20 & 0.18 & -0.27 \\
\hline 17 & 0.25 & 0.01 & 0.42 & 0 & 0 & $0.9 \%$ & $1.5 \%$ & 0.81 & 0.42 & 0.84 & 0.42 & 0.69 & 0.56 & -0.52 \\
\hline 18 & 0.25 & 0.01 & 0.42 & 0.025 & 1.37 & $0.9 \%$ & $1.9 \%$ & 0.81 & 0.31 & 0.84 & 0.31 & 0.62 & 0.41 & -0.70 \\
\hline 19 & 0.25 & 0.01 & 0.42 & 0.05 & 4.52 & $0.9 \%$ & $2.3 \%$ & 0.81 & 0.24 & 0.84 & 0.24 & 0.57 & 0.32 & -0.82 \\
\hline 20 & 0.25 & 0.01 & 0.42 & 0.075 & 11.57 & $0.9 \%$ & $2.5 \%$ & 0.81 & 0.21 & 0.84 & 0.21 & 0.55 & 0.28 & -0.89 \\
\hline 21 & 0.25 & 0.02 & 1 & 0 & 0 & $1.6 \%$ & $1.7 \%$ & 0.46 & 0.41 & 0.30 & 0.41 & 0.57 & 0.55 & -0.11 \\
\hline 22 & 0.25 & 0.02 & 1 & 0.025 & 1.37 & $1.6 \%$ & $2.1 \%$ & 0.46 & 0.30 & 0.30 & 0.30 & 0.49 & 0.40 & -0.42 \\
\hline 23 & 0.25 & 0.02 & 1 & 0.05 & 4.52 & $1.6 \%$ & $2.5 \%$ & 0.46 & 0.24 & 0.30 & 0.24 & 0.44 & 0.32 & -0.63 \\
\hline 24 & 0.25 & 0.02 & 1 & 0.075 & 11.57 & $1.6 \%$ & $2.7 \%$ & 0.46 & 0.21 & 0.30 & 0.21 & 0.42 & 0.28 & -0.75 \\
\hline 25 & 0.25 & 0.03 & 1.81 & 0 & 0 & $2.1 \%$ & $2.1 \%$ & 0.34 & 0.34 & 0.17 & 0.34 & 0.51 & 0.51 & 0.23 \\
\hline 26 & 0.25 & 0.03 & 1.81 & 0.025 & 1.37 & $2.1 \%$ & $2.3 \%$ & 0.34 & 0.30 & 0.17 & 0.30 & 0.42 & 0.40 & -0.17 \\
\hline 27 & 0.25 & 0.03 & 1.81 & 0.05 & 4.52 & $2.1 \%$ & $2.7 \%$ & 0.34 & 0.24 & 0.17 & 0.24 & 0.38 & 0.32 & -0.44 \\
\hline 28 & 0.25 & 0.03 & 1.81 & 0.075 & 11.57 & $2.1 \%$ & $2.9 \%$ & 0.34 & 0.21 & 0.17 & 0.21 & 0.36 & 0.28 & -0.60 \\
\hline 29 & 0.25 & 0.04 & 2.95 & 0 & 0 & $2.5 \%$ & $2.5 \%$ & 0.28 & 0.28 & 0.12 & 0.28 & 0.47 & 0.47 & 0.51 \\
\hline 30 & 0.25 & 0.04 & 2.95 & 0.025 & 1.37 & $2.5 \%$ & $2.5 \%$ & 0.28 & 0.28 & 0.12 & 0.28 & 0.39 & 0.39 & 0.06 \\
\hline 31 & 0.25 & 0.04 & 2.95 & 0.05 & 4.52 & $2.5 \%$ & $2.9 \%$ & 0.28 & 0.24 & 0.12 & 0.24 & 0.35 & 0.32 & -0.26 \\
\hline 32 & 0.25 & 0.04 & 2.95 & 0.075 & 11.57 & $2.5 \%$ & $3.1 \%$ & 0.28 & 0.21 & 0.12 & 0.21 & 0.33 & 0.28 & -0.44 \\
\hline
\end{tabular}


Table IV.b: Further results for various parameters values

\begin{tabular}{|c|c|c|c|c|c|c|c|c|c|c|c|c|c|c|}
\hline 1 & 2 & 3 & $3 a$ & 4 & $4 a$ & 14 & 15 & 16 & 17 & 18 & 19 & 20 & 21 & 22 \\
\hline $\mathrm{CN}$ & $\alpha$ & Annual v & Period v & Annual $\rho$ & Period $\rho$ & $\begin{array}{c}\text { Annual } \\
\text { Interest } \\
\text { Rate }\end{array}$ & $\begin{array}{c}\text { Annual } \\
\text { Interest } \\
\text { Rate I }\end{array}$ & SY & SYI & SGW & SGWI & SNW & SNWI & $\theta / \mathbf{S G W}$ \\
\hline 33 & 0.35 & 0.01 & 0.42 & 0 & 0 & $0.9 \%$ & $2.1 \%$ & 1.11 & 0.40 & 1.61 & 0.40 & 0.78 & 0.61 & -0.69 \\
\hline 34 & 0.35 & 0.01 & 0.42 & 0.025 & 1.37 & $0.9 \%$ & $2.4 \%$ & 1.11 & 0.32 & 1.61 & 0.32 & 0.72 & 0.49 & -0.80 \\
\hline 35 & 0.35 & 0.01 & 0.42 & 0.05 & 4.52 & $0.9 \%$ & $2.7 \%$ & 1.11 & 0.27 & 1.61 & 0.27 & 0.68 & 0.41 & -0.88 \\
\hline 36 & 0.35 & 0.01 & 0.42 & 0.075 & 11.57 & $0.9 \%$ & $2.8 \%$ & 1.11 & 0.25 & 1.61 & 0.25 & 0.66 & 0.38 & -0.92 \\
\hline 37 & 0.35 & 0.02 & 1 & 0 & 0 & $1.6 \%$ & $2.3 \%$ & 0.62 & 0.39 & 0.42 & 0.39 & 0.68 & 0.61 & -0.41 \\
\hline 38 & 0.35 & 0.02 & 1 & 0.025 & 1.37 & $1.6 \%$ & $2.6 \%$ & 0.62 & 0.31 & 0.42 & 0.31 & 0.60 & 0.48 & -0.60 \\
\hline 39 & 0.35 & 0.02 & 1 & 0.05 & 4.52 & $1.6 \%$ & $2.9 \%$ & 0.62 & 0.27 & 0.42 & 0.27 & 0.56 & 0.41 & -0.73 \\
\hline 40 & 0.35 & 0.02 & 1 & 0.075 & 11.57 & $1.6 \%$ & $3.1 \%$ & 0.62 & 0.25 & 0.42 & 0.25 & 0.54 & 0.38 & -0.81 \\
\hline 41 & 0.35 & 0.03 & 1.81 & 0 & 0 & $2.2 \%$ & $2.4 \%$ & 0.45 & 0.39 & 0.20 & 0.39 & 0.63 & 0.60 & -0.16 \\
\hline 42 & 0.35 & 0.03 & 1.81 & 0.025 & 1.37 & $2.2 \%$ & $2.8 \%$ & 0.45 & 0.31 & 0.20 & 0.31 & 0.54 & 0.48 & -0.41 \\
\hline 43 & 0.35 & 0.03 & 1.81 & 0.05 & 4.52 & $2.2 \%$ & $3.1 \%$ & 0.45 & 0.27 & 0.20 & 0.27 & 0.50 & 0.41 & -0.58 \\
\hline 44 & 0.35 & 0.03 & 1.81 & 0.075 & 11.57 & $2.2 \%$ & $3.3 \%$ & 0.45 & 0.25 & 0.20 & 0.25 & 0.47 & 0.38 & -0.67 \\
\hline 45 & 0.35 & 0.04 & 2.95 & 0 & 0 & $2.7 \%$ & $2.7 \%$ & 0.37 & 0.37 & 0.12 & 0.37 & 0.59 & 0.59 & 0.06 \\
\hline 46 & 0.35 & 0.04 & 2.95 & 0.025 & 1.37 & $2.7 \%$ & $3.0 \%$ & 0.37 & 0.31 & 0.12 & 0.31 & 0.51 & 0.48 & -0.22 \\
\hline 47 & 0.35 & 0.04 & 2.95 & 0.05 & 4.52 & $2.7 \%$ & $3.3 \%$ & 0.37 & 0.27 & 0.12 & 0.27 & 0.46 & 0.41 & -0.42 \\
\hline 48 & 0.35 & 0.04 & 2.95 & 0.075 & 11.57 & $2.7 \%$ & $3.5 \%$ & 0.37 & 0.25 & 0.12 & 0.25 & 0.44 & 0.38 & -0.53 \\
\hline 49 & 0.45 & 0.01 & 0.42 & 0 & 0 & $0.9 \%$ & $2.6 \%$ & 1.40 & 0.37 & 3.41 & 0.37 & 0.85 & 0.67 & -0.79 \\
\hline 50 & 0.45 & 0.01 & 0.42 & 0.025 & 1.37 & $0.9 \%$ & $2.9 \%$ & 1.40 & 0.31 & 3.41 & 0.31 & 0.80 & 0.57 & -0.86 \\
\hline 51 & 0.45 & 0.01 & 0.42 & 0.05 & 4.52 & $0.9 \%$ & $3.1 \%$ & 1.40 & 0.28 & 3.41 & 0.28 & 0.77 & 0.51 & -0.91 \\
\hline 52 & 0.45 & 0.01 & 0.42 & 0.075 & 11.57 & $0.9 \%$ & $3.2 \%$ & 1.40 & 0.26 & 3.41 & 0.26 & 0.75 & 0.48 & -0.94 \\
\hline 53 & 0.45 & 0.02 & 1 & 0 & 0 & $1.7 \%$ & $2.8 \%$ & 0.77 & 0.37 & 0.56 & 0.37 & 0.77 & 0.67 & -0.59 \\
\hline 54 & 0.45 & 0.02 & 1 & 0.025 & 1.37 & $1.7 \%$ & $3.1 \%$ & 0.77 & 0.31 & 0.56 & 0.31 & 0.70 & 0.57 & -0.71 \\
\hline 55 & 0.45 & 0.02 & 1 & 0.05 & 4.52 & $1.7 \%$ & $3.3 \%$ & 0.77 & 0.28 & 0.56 & 0.28 & 0.66 & 0.51 & -0.80 \\
\hline 56 & 0.45 & 0.02 & 1 & 0.075 & 11.57 & $1.7 \%$ & $3.5 \%$ & 0.77 & 0.26 & 0.56 & 0.26 & 0.64 & 0.48 & -0.85 \\
\hline 57 & 0.45 & 0.03 & 1.81 & 0 & 0 & $2.3 \%$ & $3.0 \%$ & 0.55 & 0.37 & 0.20 & 0.37 & 0.72 & 0.67 & -0.39 \\
\hline 58 & 0.45 & 0.03 & 1.81 & 0.025 & 1.37 & $2.3 \%$ & $3.3 \%$ & 0.55 & 0.31 & 0.20 & 0.31 & 0.64 & 0.56 & -0.55 \\
\hline 59 & 0.45 & 0.03 & 1.81 & 0.05 & 4.52 & $2.3 \%$ & $3.5 \%$ & 0.55 & 0.28 & 0.20 & 0.28 & 0.60 & 0.50 & -0.67 \\
\hline 60 & 0.45 & 0.03 & 1.81 & 0.075 & 11.57 & $2.3 \%$ & $3.7 \%$ & 0.55 & 0.26 & 0.20 & 0.26 & 0.58 & 0.48 & -0.73 \\
\hline 61 & 0.45 & 0.04 & 2.95 & 0 & 0 & $2.8 \%$ & $3.2 \%$ & 0.44 & 0.37 & 0.10 & 0.37 & 0.69 & 0.66 & -0.21 \\
\hline 62 & 0.45 & 0.04 & 2.95 & 0.025 & 1.37 & $2.8 \%$ & $3.5 \%$ & 0.44 & 0.31 & 0.10 & 0.31 & 0.61 & 0.56 & -0.39 \\
\hline 63 & 0.45 & 0.04 & 2.95 & 0.05 & 4.52 & $2.8 \%$ & $3.7 \%$ & 0.44 & 0.28 & 0.10 & 0.28 & 0.56 & 0.50 & -0.53 \\
\hline 64 & 0.45 & 0.04 & 2.95 & 0.075 & 11.57 & $2.8 \%$ & $3.8 \%$ & 0.44 & 0.26 & 0.10 & 0.26 & 0.54 & 0.47 & -0.60 \\
\hline
\end{tabular}




\section{IZA Discussion Papers}

No Author(s)

161

V. Gimpelson

D. Treisman

G. Monusova

162

C. Dustmann

M. E. Rochina-

Barrachina

R. A. Hart

Y. Ma

164 M. A. Shields

S. Wheatley Price

165

A. Barrett

J. FitzGerald

B. Nolan

G. S. Epstein

A. L. Hillman

R. Winkelmann

T. K. Bauer

K. F. Zimmermann

C. Dustmann

F. Windmeijer

D. Card

D. S. Hamermesh

E. Fehr

J.-R. Tyran

M. Lofstrom

W. Meyer

Titel

Area

Date

Public Employment and Redistributive Politics:

4

$6 / 00$

Evidence from Russia's Regions

Selection Correction in Panel Data Models: An 6

Application to Labour Supply and Wages

Why do Firms Pay an Overtime Premium?

5

$6 / 00$

Racial Harassment, Job Satisfaction and Intentions

5

$6 / 00$

to Quit: Evidence from the British Nursing Profession

Immigration in a High Unemployment Economy: 1

$6 / 00$ The Recent Danish Experience

The Impact of Alcohol Consumption on Occupa- 5 tional Attainment in England

$6 / 00$

Earnings Inequality, Returns to Education and 5 Immigration into Ireland

$6 / 00$

Social Harmony at the Boundaries of the Welfare 3 State: Immigrants and Social Transfers

$6 / 00$

Immigration Policies and their Impact: The Case of 1

$7 / 00$

New Zealand and Australia

Immigration Policy in Integrated National

$7 / 00$

Economies

Wages and the Demand for Health - A Life Cycle 5

$7 / 00$

Analysis

Reforming the Financial Incentives of the Welfare 3

System

$7 / 00$

Timing, Togetherness and Time Windfalls

$7 / 00$

Does Money Illusion Matter? An Experimental

7

$7 / 00$

Approach

Self-Employment and Earnings among High-

Skilled Immigrants in the United States

Industrial Relations and the Wage Differentials

5

$7 / 00$ between Skilled and Unskilled Blue-Collar

Workers within Establishments: An Empirical

Analysis with Data of Manufacturing Firms 
177 B. R. Chiswick

G. Repetto

178 R. Euwals M. Ward

179 E. Wasmer

P. Weil

180 T. K. Bauer

I. N. Gang

181 E. Wasmer

Y. Zenou

182 M. Fertig

C. M. Schmidt

183 M. Fertig

C. M. Schmidt

184 M. Corak

B. Gustafsson

T. Österberg

185

H. Bonin

K. F. Zimmermann

186

C. Dustmann

T. K. Bauer

M. Lofstrom

K. F. Zimmermann

188 A. Kapteyn

A. S. Kalwij

A. Zaidi

189 W. Arulampalam

190

C. Dustmann

I. Preston

191

G. C. Giannelli

C. Monfardini

192

G. Brunello

A. Kunze
Immigrant Adjustment in Israel: Literacy and

Fluency in Hebrew and Earnings

The Renumeration of British Academics

The Macroeconomics of Labor and Credit Market Imperfections

Sibling Rivalry in Educational Attainment:

The German Case

Space, Search and Efficiency

2

Discretionary Measures of Active Labor Market

Policy: The German Employment Promotion Reform in Perspective

Aggregate-Level Migration Studies as a Tool for 1 Forecasting Future Migration Streams

Intergenerational Influences on the Receipt of

3

Unemployment Insurance in Canada and Sweden

The Post-Unification German Labor Market

4

$8 / 00$

Temporary Migration and Economic Assimilation

$8 / 00$

Immigration Policy, Assimilation of Immigrants and Natives' Sentiments towards Immigrants: Evidence from 12 OECD-Countries

The Myth of Worksharing

Is Unemployment Really Scarring? Effects of Unemployment Experiences on Wages

Racial and Economic Factors in Attitudes to Immigration

Joint Decisions on Household Membership and Human Capital Accumulation of Youths: The role of expected earnings and local markets

Absolute Risk Aversion and the Returns to Education

The Determination of Wages and the Gender Wage Gap: A Survey 
195 F. Büchel

A. Mertens

196 J. S. Earle

K. Z. Sabirianova

197

G. A. Pfann

198 M. Kreyenfeld

C. K. Spiess

G. G. Wagner

199 H. Entorf

200 T. Bauer

G. S. Epstein

I. N. Gang

201 T. J. Dohmen

G. A. Pfann

202

P. Francois

J. C. van Ours

203
J. M. Abowd
F. Kramarz
D. N. Margolis
T. Philippon

204

G. S. Epstein
A. L. Booth
M. Francesconi
J. Frank

206 C. M. Schmidt

R. Baltussen

R. Sauerborn

C. M. Schmidt

J. Hartog

R. Winkelmann

209 M. Barbie

M. Hagedorn

A. Kaul

210 T. J. Dohmen
Overeducation, Undereducation, and the Theory

of Career Mobility

Equilibrium Wage Arrears: A Theoretical and 4

Empirical Analysis of Institutional Lock-In

Options to Quit

1

$9 / 00$

A Forgotten Issue: Distributional Effects of Day 3

Care Subsidies in Germany

Rational Migration Policy Should Tolerate Non-

Zero Illegal Migration Flows: Lessons from

Modelling the Market for Illegal Migration

What are Migration Networks?

$9 / 00$

Worker Separations in a Nonstationary Corporate 1 Environment

Gender Wage Differentials in a Competitive Labor Market: The Household Interaction Effect

The Tail of Two Countries: Minimum Wages and 5 Employment in France and the United States

5

$9 / 00$

$9 / 00$

Labor Market Interactions Between Legal and

1

$10 / 00$ Illegal Immigrants

Temporary Jobs: Stepping Stones or Dead Ends? 1

$10 / 00$

The Evaluation of Community-Based Interventions: Group-Randomization, Limits and Alternatives

Arbeitsmarktpolitische Maßnahmen und ihre

6

$10 / 00$

Evaluierung: eine Bestandsaufnahme

Dutch Migrants in New Zealand:

Did they Fare Well?

1

$10 / 00$

Dynamic Effciency and Pareto Optimality in a

3

$10 / 00$ Stochastic OLG Model with Production and Social Security 

211 A. van Soest
M. Das
X. Gong
212 X. Gong
A. van Soest
P. Zhang
213 X. Gong
A. van Soest
E. Villagomez

214 X. Gong

A. van Soest

215 J. Ermisch

M. Francesconi

216 F. Büchel

217 J. Hansen

R. Wahlberg

218 C. Dustmann

A. van Soest

219 F. Kramarz

T. Philippon

220 W. A. Cornelius

E. A. Marcelli

221

C. Grund

222 W.P.M. Vijverberg

223 M. Rosholm

M. Svarer

224

J. Schwarze

225

L. Modesto

J. P. Thomas
A Structural Labour Supply Model with

The Effects of Overeducation on Productivity in Mexico

Wages as Risk Compensation in Germany 

former Soviet Union to Israel: Who is coming when? 

of Labor Income Risk and Car Insurance in the UK 1969-95

241 W. Koeniger

242 G. Faggio J. Konings

243

E. Brainerd

244 S. M. Fuess, Jr. M. Millea

246 E. Plug W. Vijverberg

247 E. Plug W. Vijverberg

248 P. M. Picard E. Toulemonde

249 B. M. S. van Praag P. Cardoso
Trade, Labor Market Rigidities, and GovernmentFinanced Technological Change

Job Creation, Job Destruction and Employment Growth in Transition Countries in the 90's

Economic Reform and Mortality in the Former 4 Soviet Union: A Study of the Suicide Epidemic in the 1990s

Pay and Productivity in a Corporatist Economy: 5 $01 / 01$ Evidence from Austria

Globalization and Human Capital Formation

5

$01 / 01$

Schooling, Family Background, and Adoption:

5

$01 / 01$ Does Family Income Matter?

Schooling, Family Background, and Adoption:

5 Is it Nature or is it Nurture?

The Impact of Labor Markets on Emergence and 2 Persistence of Regional Asymmetries Retirement Benefit Systems 